\title{
IMPACT OF TEC FLUCTUATIONS IN THE ANTARCTIC IONOSPHERE ON GPS POSITIONING
}

\author{
Andrzej Krankowski ${ }^{1}$, Irk I. Shagimuratov ${ }^{2}$ \\ ${ }^{1}$ Institute of Geodesy, University of Warmia and Mazury, Oczapowski St.1, \\ 10-957 Olsztyn, Poland, e-mail: kand@uwm.edu.pl \\ ${ }^{2}$ WD IZMIRAN, Kaliningrad, RUSSIA
}

\begin{abstract}
With increasing reliance on space-based platforms for global navigation and communication, concerns about the impact of ionospheric scintillation and total electron content fluctuations on these systems have became a high priority. In this paper, GPS transionospheric signals have been used to study the development of ionospheric phase fluctuations observed at Antarctic IGS permanent stations: McMurdo-MCM4, Casey-CAS1, Mawson-MAW1, Sanae-VESL, Syowa-SYOG and Davis-DAV1 in 2001. The use of the multi-station, multi-path observations of the GPS beacons has allowed the study of the time development of irregularities as a function of latitude and longitude of individual geomagnetic storms. The basic storms studied were those of March 19-20, March 31, April 9-11, June 1617, and September 23, 2001. The rate of TEC (ROT) parameter was used to study the occurrence of TEC fluctuations. The results from studying these storms showed the unique nature of each storm. For the above five storms, data were available from three auroral stations (VESL, SYOG and MAW1) and from $61^{\circ}$ to $70^{\circ}$ Corrected Geomagnetic Latitude (CGL). In addition, data from three higher latitude polar stations (DAV1, MCM4 and CAS1) near $80^{\circ}$ CGL are also analysed.
\end{abstract}

Fluctuation effects, causing dramatic changes in total electron content - TEC, can have a different impact on GPS positioning accuracy (especially during phase ambiguity resolution). Bernese ver.4.2 software was used for the analysis of the GPS permanent data from Antarctic IGS stations. The analyses rely on studying the repeatability of vector co-ordinates. These vectors were investigated during the geomagnetic storms when the intensity of TEC fluctuations was more pronounced.

The impact of TEC fluctuations in the high latitude ionosphere on GPS positioning accuracy has been discussed in terms of the total number of observations of doubledifferences (DD) and in the ratio of the total number of all ambiguities to unresolved ones.

Keywords: ionosphere, TEC, geomagnetic storms, phase fluctuation, GPS, ambiguity resolution

\section{INTRODUCTION}

Ionospheric irregularities at high latitudes are of interest to users of satellite transmissions and those studying aeronomy. With the advent of the GPS system and the use of GPS for geodesy, a network of stations has been reporting data on a continuous basis. Total electron content (TEC) data are recorded every $30 \mathrm{~s}$. In the polar regions, irregularities are common. These 
irregularities on a different scale cause fluctuations in the total electron content (TEC fluctuations). Large-scale fluctuations are caused by ionospheric irregularities whose scale is larger than 100-300 km. and occur as deep spatial variations of TEC. Irregularities of about ten kilometers cause scintillation effects. The intensive phase fluctuations observed along GPS satellite passes are caused by dramatic changes in total electron content (TEC) and demonstrate a strong horizontal gradient of TEC. Fluctuation effects and TEC gradients can have a different impact on GPS measurements and data processing for high-precision GPS positioning. They affect phase ambiguity resolution, increase the number of undetected and uncorrected cycle slips and loss of signal lock (Wanninger, 1993; Krankowski et al., 2002).

The development of TEC fluctuations over Antarctic regions of the Earth has been studied with distinct satellite transmissions over several years. MacDougall (1990) found average phase and amplitude scintillation occurrence at high latitudes while working with three stations. He found maximum phase scintillation at Churchill and Tromso in the auroral oval. The phase scintillation increased along an L shell when the station was under the auroral oval. Kersley et al. (1988a,b,c, 1989, 1995) studied amplitude and phase scintillation at high latitudes for seasonal patterns and for distinct storms. These studies and others (Basu, Su. et al. 1983, 1984, 1993: Basu, S. et al. 1999) have shown a general correlation between amplitude and TEC fluctuation occurrence.

Recently, several researchers (Aarons, 1997: Aarons et al., 2000; Coker et al., 1995; Hargreaves and Burns, 1996; Krankowski et al., 2005) also used GPS permanent observations to study irregularities in the auroral region. Wanninger (1995), Doherty et al. (1994) have utilized the GPS data at $30 \mathrm{~s}$ intervals to study ionospheric irregularities of electron density by computing the time rate of the change of the differential carrier phase. This is an equivalent to the rate of the change of the total electron content, termed ROT, in units of TEC/min. Aarons et al. (1997), Aarons (1997) and Krankowski et al. (2005) have demonstrated the utility of such a dataset for studying the evolution of different scale irregularities during magnetic storms at high latitudes. Pi et al. (1997) have defined a rate of change of TEC index (ROTI) based on standard deviation of ROT over a 5-min period. This index statistically quantifies the ROT measurements.

In precise GPS positioning, based on double-differenced (DD) carrier-phase observables, the key issue is to resolve the ambiguities to their integer values, and to derive an improved estimator of the baseline coordinates (i.e., fixed solution). Therefore, the ambiguity resolution (AR) performance determines the quality of the resulting position coordinates. In this paper, the results of the development of TEC fluctuations and their impact on GPS positioning accuracy (especially on ambiguity resolution and the decrease of the number of GPS observations of double-difference) is presented for magnetic storms occurring on March 19-20, March 31, April 9-11, June 17-18 and September 23, 2001. Bernese ver.4.2 software (Hugentobler et al., 2001) with the Quasi-Ionosphere-Free (QIF) ambiguity resolution was used for the analysis of the GPS permanent data from Antarctic IGS stations.

Krankowski et al. (2002) demonstrated the analyses of the influence of the geomagnetic storms on positioning precision over the Arctic region. The results have shown a strong dependence between TEC changes and the repeatability of the North, East and Up vector components. The motivation of this study was to explain if knowledge of intensive TEC fluctuations might be utilized for improving the repeatability of the vector components during severe geomagnetic disturbances. 


\section{LOCATIONS OF STATIONS}

GPS permanent observations carried out at six Antarctic IGS stations (McMurdo-MCM4, Casey-CAS1, Mawson-MAW1, Sanae-VESL, Syowa-SYOG and Davis-DAV1) were used in this study. Fig. 1 and Table 1 present a map and the geographic and corrected geomagnetic coordinates of the stations, respectively. GPS stations cover a wide longitudinal area of the ionosphere, which makes it possible to describe the temporal development of fluctuations at a similar geomagnetic latitude from auroral (VESL, SYOG, MAW1) to polar (MCM4, CAS1, DAV1) stations.

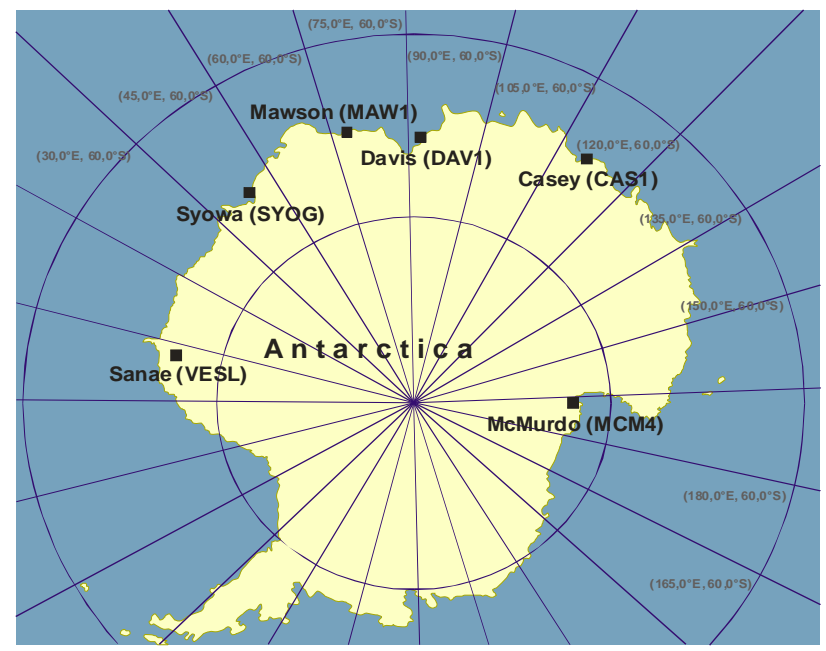

Fig. 1. Geographic map of high latitude GPS stations used in this study

Table 1. Geographic and Corrected Geomagnetic Latitudes of Antarctic IGS stations

\begin{tabular}{|l|c|l|}
\hline Station & $\begin{array}{l}\text { Geographic } \\
\text { latitude }\end{array}$ & $\begin{array}{l}\text { Corrected } \\
\text { Geomagnetic } \\
\text { Latitude }\end{array}$ \\
\hline Sanae (VESL) & -71.67 & -61.67 \\
\hline Syowa (SYOG) & -69.01 & -66.65 \\
\hline Mawson (MAW1) & -67.60 & -70.68 \\
\hline Davis (DAV1) & -68.58 & -74.91 \\
\hline McMurdo(MCM4) & -77.84 & -79.95 \\
\hline Casey (CAS1) & -66.28 & -80.66 \\
\hline
\end{tabular}

\section{GEOMAGNETIC STORMS}

The Kp plots for several magnetic storms in 2001 used in this study are shown in Fig.2. For the March 19-20 geomagnetic storm, the main phase of the storm started at 11 UT on March 19. The maximum of $K_{p}$ index amounted to 7 . The second investigated storm started about 04 UT on March 31. This storm peaked from 06 to 12 UT when the Kp index increased sharply to value of 9 (Fig 2a). 

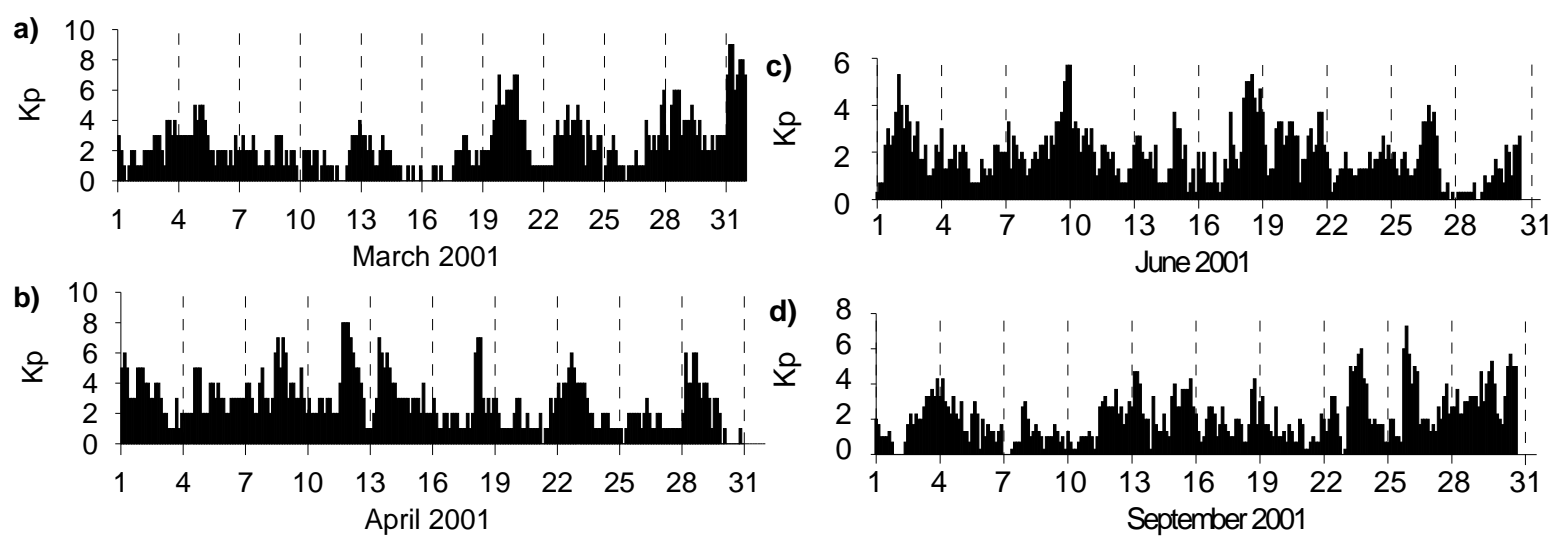

Fig. 2. Kp variations for all geomagnetic storms in 2001

The April 9-11 storm peaked from 18 to 24 UT on April 11 (Fig. 2b), the June 17-18, 2001 storm peaked from 07 to 21 UT on June 18 (Fig. 2c) and the September 23 storm peaked from 14 to 22 UT (Fig. 2d).

\section{DATA SOURCE AND RATE OF CHANGE OF TEC DATA}

The dual frequency carrier phase data from the Antarctic IGS receivers at $30 \mathrm{~s}$ intervals were used to determine the total electron content (Baran et al., 1997; Krankowski et al., 2005). Phase fluctuations were obtained by examining the $30 \mathrm{~s}$ values of total electron content (TEC). Each $30 \mathrm{~s}$ data point is obtained from the phase difference between the $1.2 \mathrm{GHz}$ and the $1.6 \mathrm{GHz}$ signals of each satellite. The rate of change of the value from a $30 \mathrm{~s}$ reading to another 1 min later is the source of the phase fluctuations reported (Wanninger, 1995; Krankowski et al., 2005; Pi et al., 1997). The propagation paths depicted are at the $400 \mathrm{~km}$ altitude intersection with corrections for obliquity.

Fig. 3 shows an example of equivalent vertical TEC variations for selected GPS satellites: 15, 18 and 28 PRNs (Zarraoa and Sardon, 1996; Jakowski, 1996) observed simultaneously at Casey, Davis and McMurdo stations during severe geomagnetic storms on 19 and 31 March, 2001, respectively. The picture clearly demonstrates that TEC variations for individual satellite passes both during disturbed and quiet days were different. It was well pronounced for the highest latitude polar stations (MCM4 and CAS1) near $80^{\circ}$ CGL. 

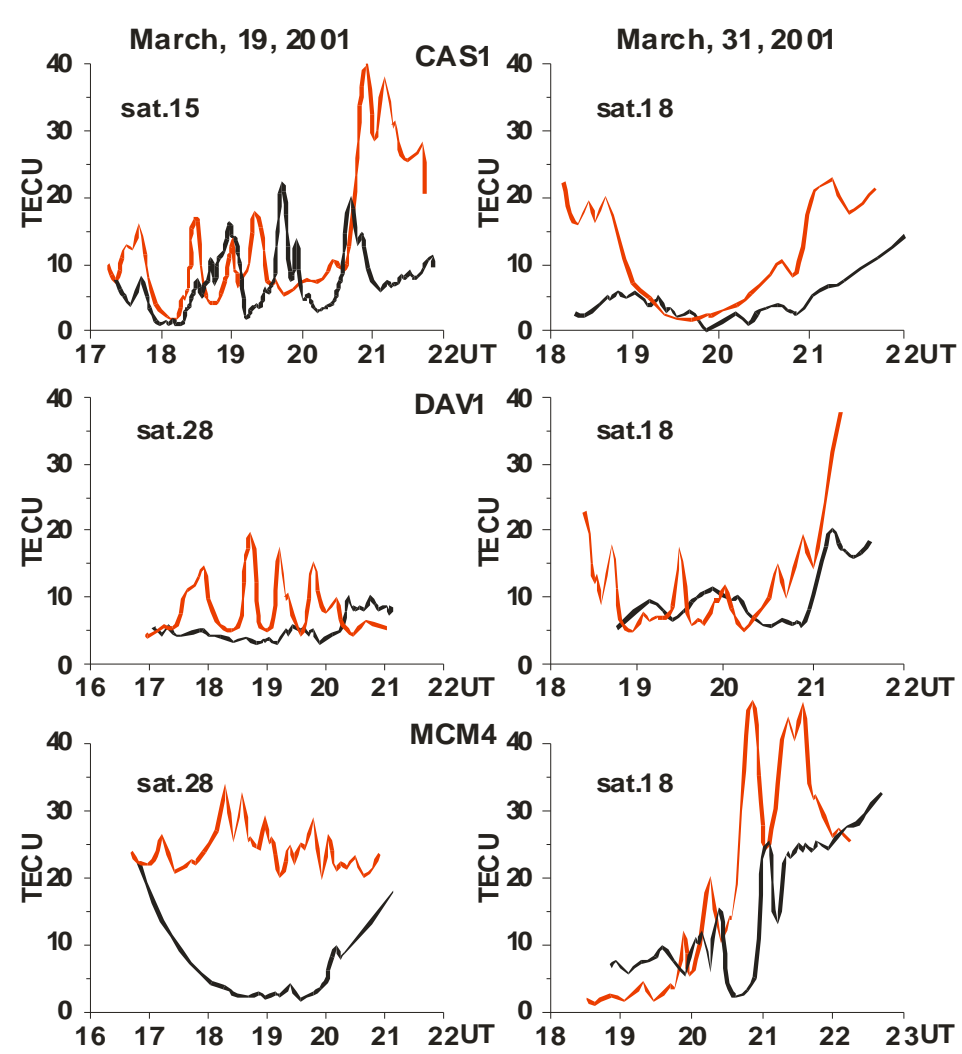

Fig. 3. TEC variations for selected satellites observed at different stations (CAS1, DAV1, and MCM4) during storms (19 and 31 March - red line, respectively) and quiet periods (17 and 26 March - black line, respectively).

\section{THE OCCURRENCE OF TEC FLUCTUATIONS OBSERVED IN GPS PHASE MEASUREMENTS}

Strong TEC fluctuations are a common feature of the polar ionosphere. TEC eruptions during geomagnetic storms are recognized as enhanced structures, relative to the background (quiet days). The development of TEC fluctuations is clearly exhibited in time variations in the dual frequency carrier phase along satellite passes.

For example, vertical TEC variations for selected GPS satellites, observed simultaneously at different polar Antarctic stations on 9,11 April and 23 September 2001, are presented in Figures 4 and 5 (black line). The enhancement of TEC can exceed 20 TECU relative to the background. A very striking structure was observed about 19:50 UT on 11 April 2001 at the highest latitude-station - Macmurdo (MCM4). The eruption of TEC with enhancements of absolute level of TEC ( $\sim 50$ TECU) was detected. The rate of changes of TEC (ROT) at the same stations and selected satellites is also presented on the panels of Figures 4 and 5 (red line). Peak ROT with values of $6 \mathrm{TEC} / \mathrm{min}$ was also registered at MCM4. At CAS1 and DAV1 stations the intensity of TEC fluctuations was less pronounced. Extreme values of ROT, i.e. 3-4 TEC/min, were observed here. 

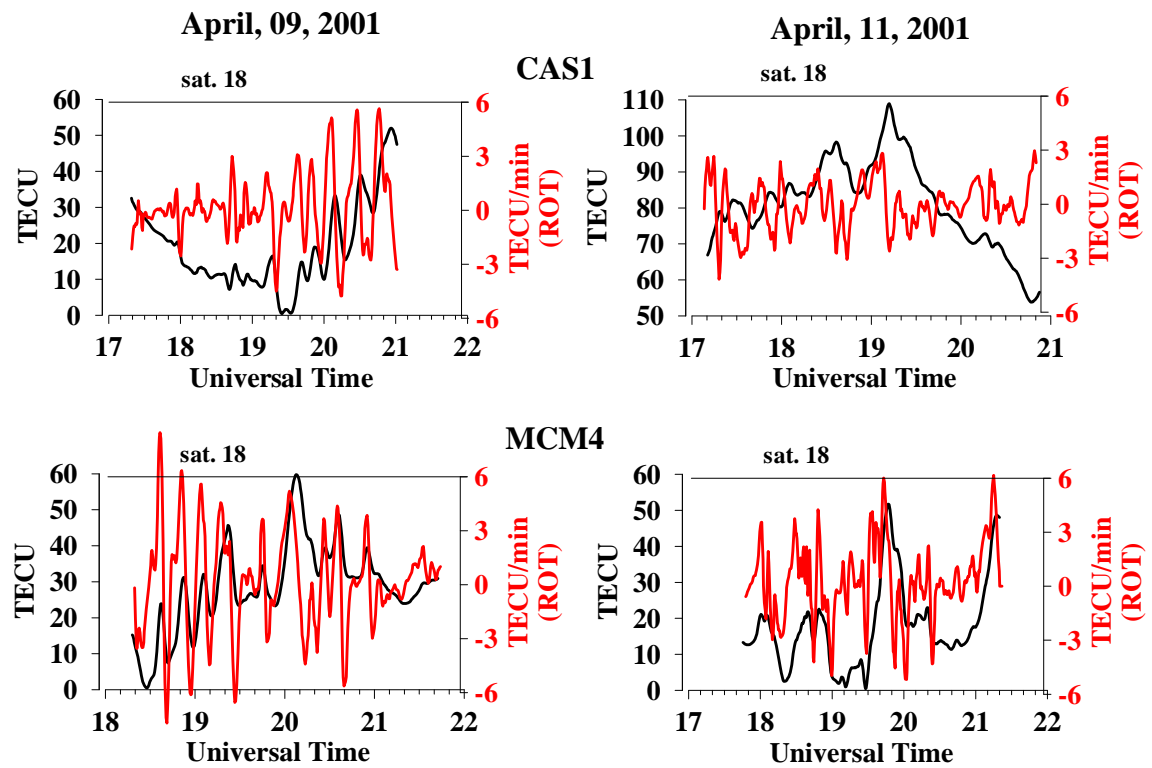

Fig. 4. TEC variations (black line) and the rate of TEC changes - ROT (red line) for satellite of PRN 18 observed at CAS1 and MCM4 stations on April 9, 2001 (left panel) and on April 11, 2001 (right panel).

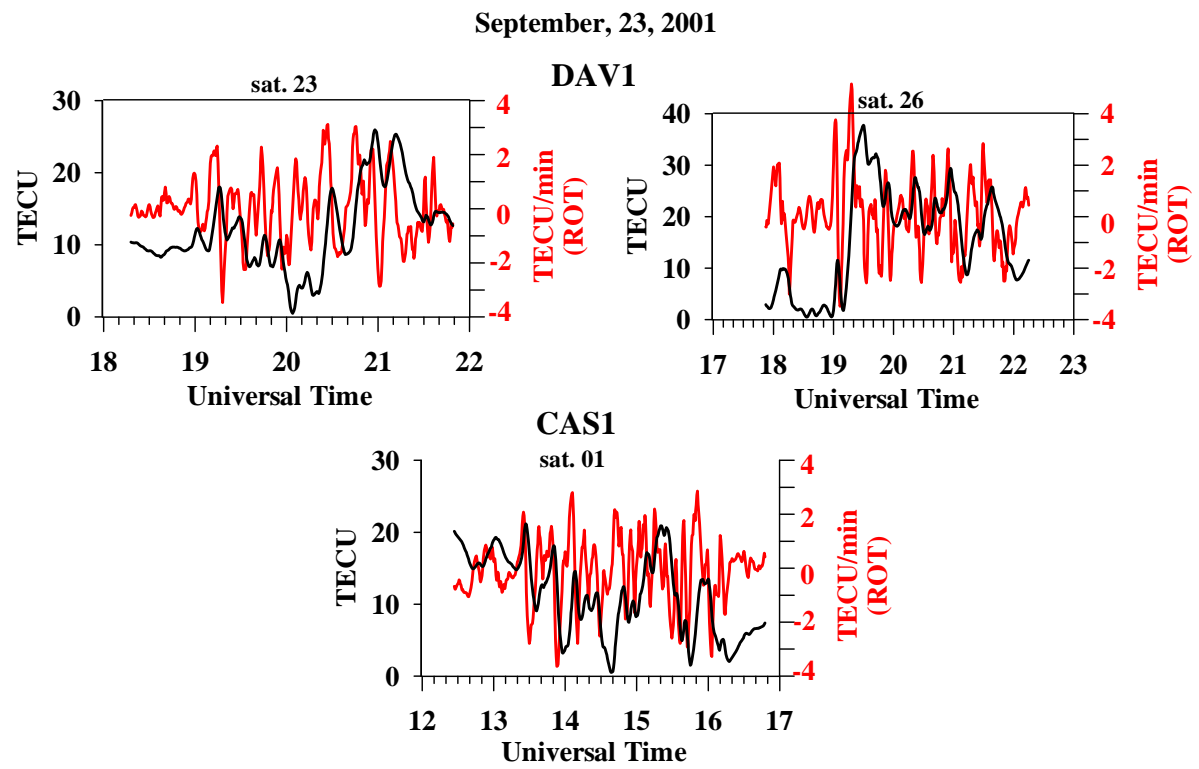

Fig. 5. TEC variations (black line) and the rate of TEC changes - ROT (red line) for selected satellites observed at DAV1 and CAS1 stations on September 23, 2001. 

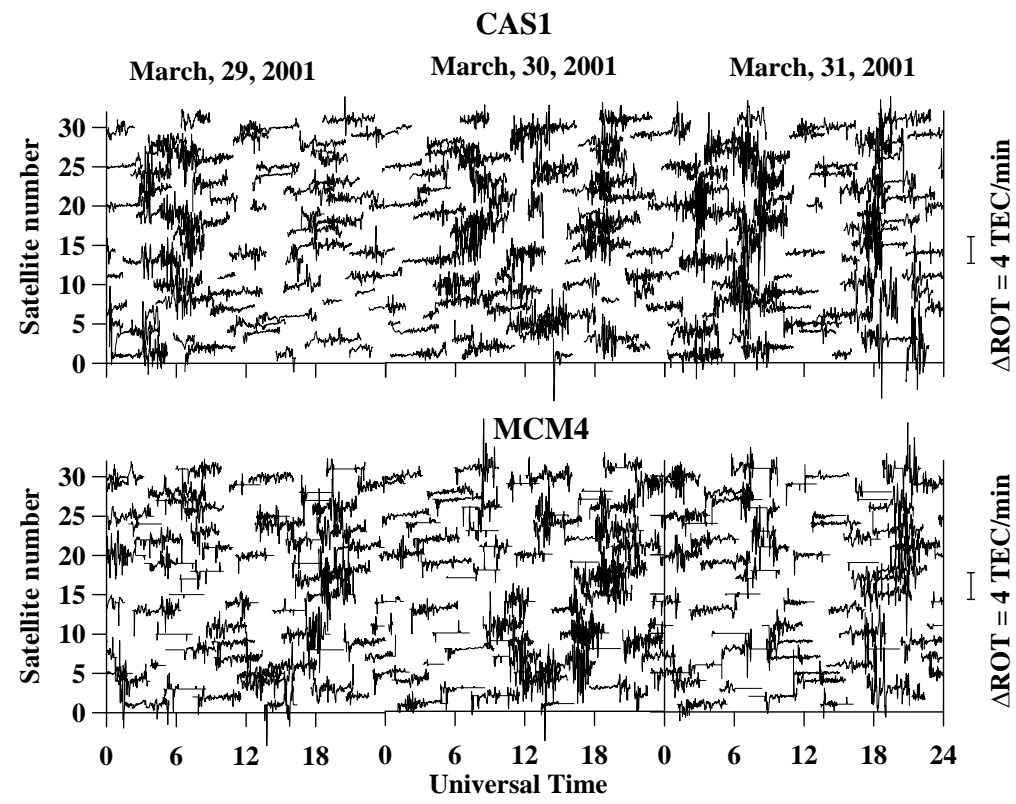

Fig. 6. The phase fluctuations (ROT) occurrence at CAS1 and MCM4 stations on 29-31 March, 2001 for all individual satellite passes.

\section{CAS1}
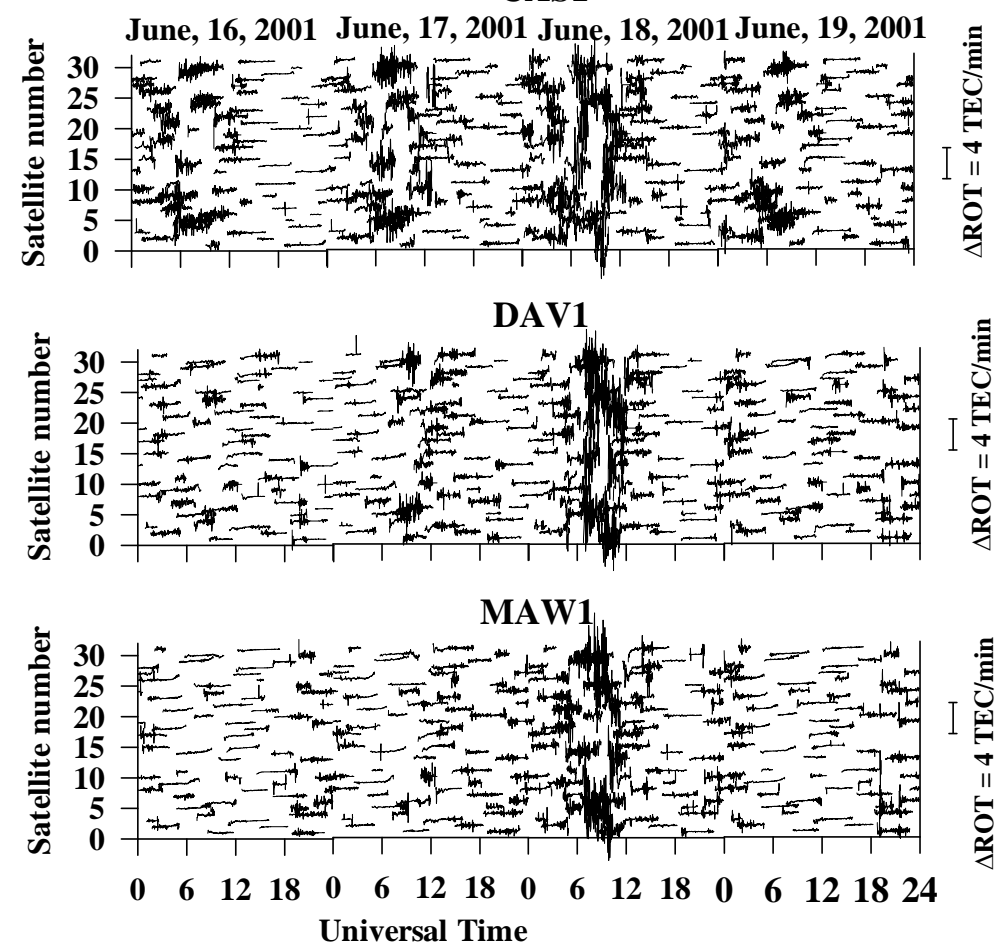

Fig.7. The phase fluctuations (ROT) occurrence at CAS1 DAV1 and MAW1 stations on 16-19 June, 2001 for all individual satellite passes.

A detailed analysis of the development of TEC fluctuations using ROT, for three geomagnetic storms: 29-31 March, 16-19 June and 21-24 September, 2001 is presented in Figures 6-8. These pictures present the occurrence of TEC fluctuations for all passes of satellites observed at CAS1, MCM4, DAV1 and MAW1 over a 24-hour interval on quiet and 
disturbed days. The analyses show that the occurrence of TEC fluctuations depend on substorm activity. All events demonstrate that the rate of TEC was maximal on most disturbed days of 31 March, 18 June and 23 September 2001 over all stations.
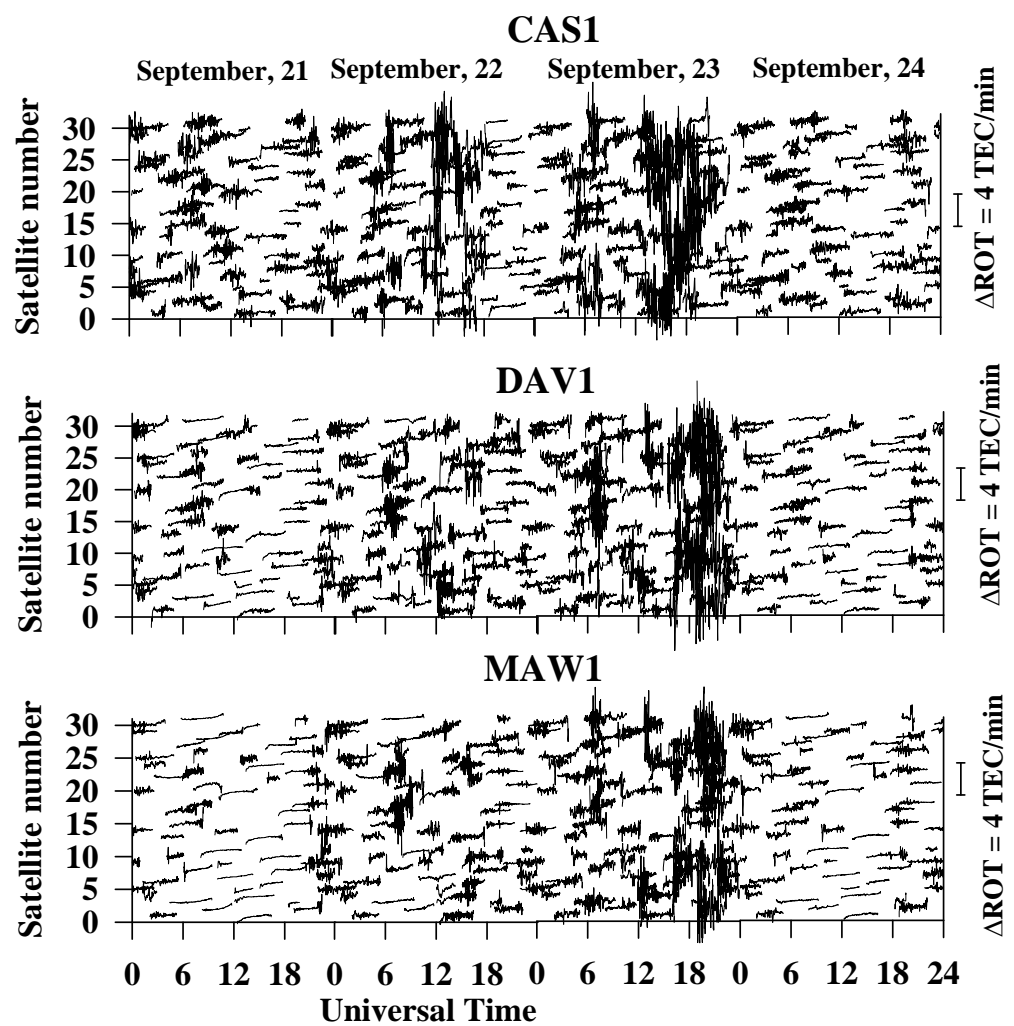

Fig. 8. The phase fluctuations (ROT) occurrence at CAS1 DAV1 and MAW1 stations on 2124 September, 2001 for all individual satellite passes.

At the stations MAW1 and DAV1, the pictures of the development of phase fluctuations were similar both on quiet and disturbed days (Figures 7 and 8). Diurnal variations in TEC fluctuations reached a minimum about 13-17 UT (on 18 June 2001) and 10-14 UT (on 23 September 2001) and maximum about 06-12 UT (on 18 June 2001) and 14-18 UT (on 23 September 2001). At the polar stations CAS1 and MCM4, the picture of the development of TEC fluctuations was more complex (Fig. 6). On the disturbed day of 31 March, the occurrence of TEC fluctuations at these stations was similar. Sometimes the occurrence of fluctuations at CAS1 and MCM4 was different. It was well pronounced for the quiet days of 29 and 30 March where the patterns were different.

\section{NUMERICAL EXPERIMENTS, ANALYSIS AND RESULTS}

The problem of reliable evolution of the impact of TEC fluctuations on GPS positioning accuracy (especially on the decrease in the number of observations of double-difference and ambiguity resolution) can be investigated using the analyses of the repeatability of GPS vector solutions. This impact was tested on selected Antarctic vectors of the IGS network, where the strong TEC fluctuations are common during geomagnetic disturbances. The distance between the selected reference stations varied from $636 \mathrm{~km}$ to $2174 \mathrm{~km}$ (Table 2).

The Bernese ver. 4.2 software package with L3 combinations and the Quasi-IonosphereFree (QIF) ambiguity resolution was used in these analyses. With Bernese software, GPS solutions were obtained from processing 8 h sessions over one month in March, April, June and September 2001. Chosen data represent both quiet and severely disturbed geomagnetic 
conditions (see Section 3). Examples of the results for representative vectors: Mawson Davis $(636 \mathrm{~km})$, Davis - Casey $(1397 \mathrm{~km})$ and Casey - McMurdo (2174 km) located in auroral and higher latitude polar ionosphere are presented in the paper.

Table 2. The lengths of the analysed baselines

\begin{tabular}{|c|c|c|c|}
\hline Baseline & $\begin{array}{c}\text { Distance } \\
(\mathbf{k m})\end{array}$ & Baseline & $\begin{array}{c}\text { Distance } \\
(\mathbf{k m})\end{array}$ \\
\hline Sanae - Syowa & 1582 & Syowa - Mawson & 966 \\
\hline Mawson - Davis & 636 & Davis - Casey & 1397 \\
\hline Casey - McMurdo & 2174 & \multicolumn{2}{|l}{} \\
\cline { 1 - 2 } & &
\end{tabular}

The influence of TEC fluctuation effects on GPS positioning accuracy has been discussed in terms of the total number of observations of double-differences (DD) and in the ratio of the total number of all ambiguities to unresolved ones.

The results obtained for the most disturbed periods at high solar activity (March-April, June and September 2001) are shown in Figures 9 - 17. These figures illustrate the relationship between the decrease in the number of DD observables (panel a) and deterioration of AR (panel b) during occurrences of deep TEC fluctuations. Since these fluctuations are observed very frequently at polar stations (MCM4 and CAS1), even during minor geomagnetic storms, this relationship is detected many times in the representative periods. It is clearly visible in Figs. 9, 12 and 15. The analyses of the disturbed day of 11 April when strong TEC fluctuations reached 6 TECU/min over McMurdo and Casey stations, show that during this day, at the same time, the total number of DD observations over the CAS1-MCM4 vector decreased to 2000. Simultaneously, the total number of all ambiguities and unresolved ones increased sharply to 190 and 170, respectively (Fig. 9). The results received for the MCM4-CAS1 vector in other disturbed periods of 18 June and 23 September were similar to those obtained during March-April 2001. For 18 June and 23 September 2001, the ratio of the total number of all ambiguities to unresolved ones was in the ratio of 100:80 and 115:105, respectively. (Figs. 12 and 15).

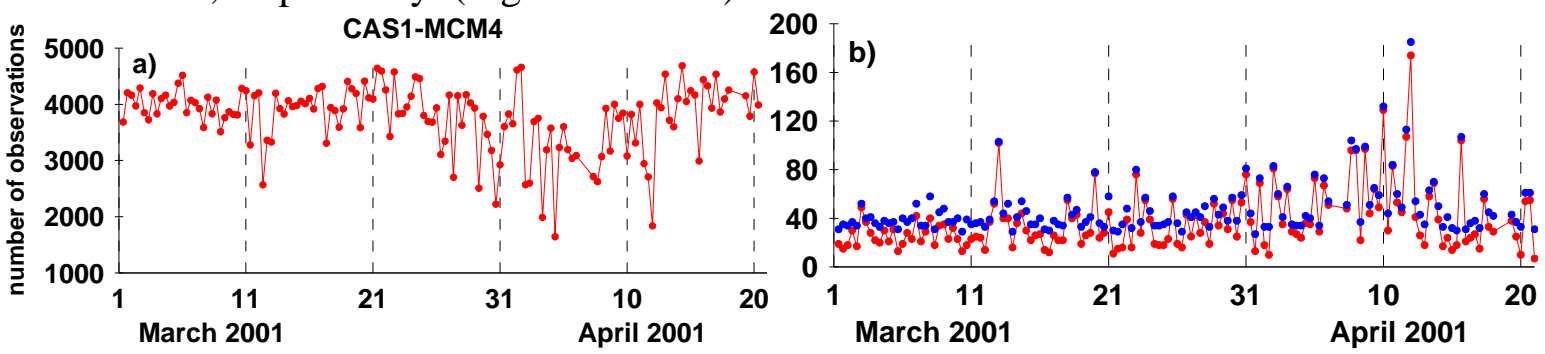

Fig. 9. Total number of observations of double-differences (a), the total number of all ambiguities (blue circles) and unresolved ambiguities (red circles) for CAS1-MCM4 vector in March-April 2001 (b)

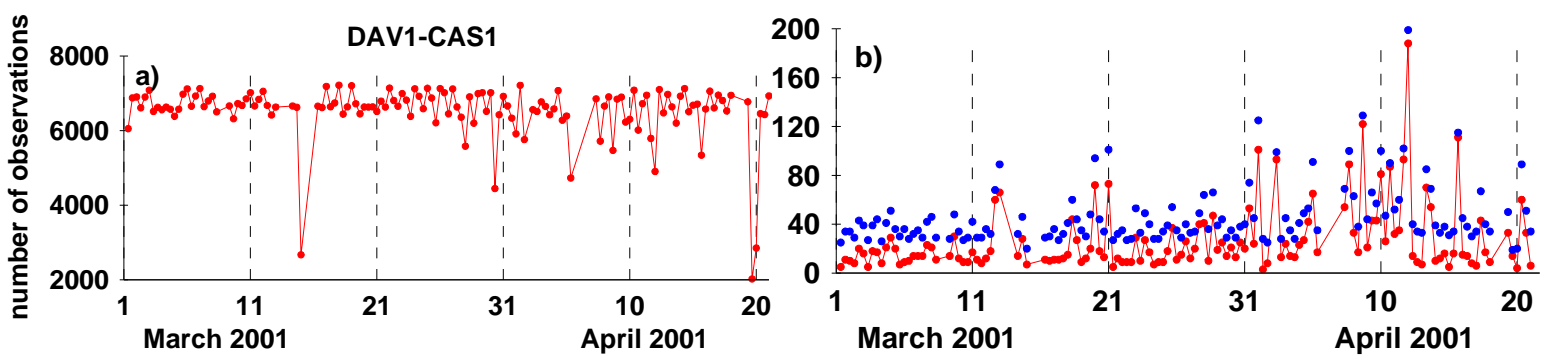

Fig. 10. Total number of observations of double-differences (a), the total number of all ambiguities (blue circles) and unresolved ambiguities (red circles) for DAV1-CAS1 vector in March-April 2001 (b) 


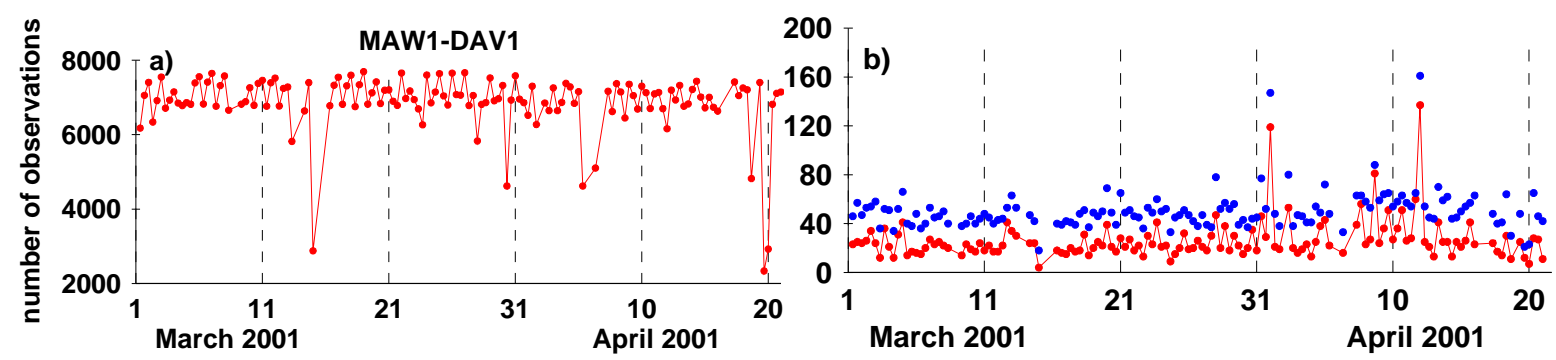

Fig. 11. Total number of observations of double-differences (a), the total number of all ambiguities (blue circles) and unresolved ambiguities (red circles) for MAW1-DAV1 vector in March-April 2001 (b)

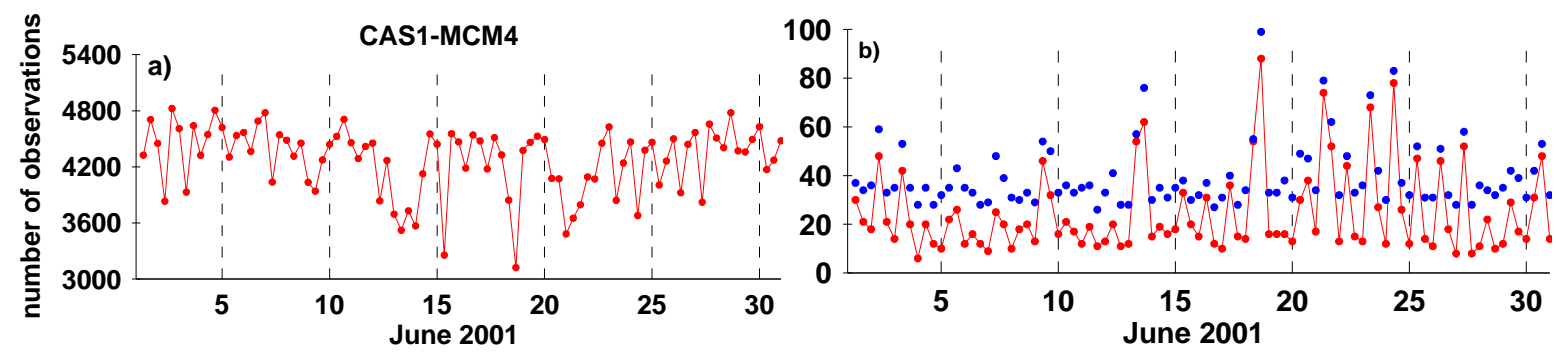

Fig. 12. Total nember of observations of double-differences (a), the total nember of all ambiguities (blue circles) and unresolved ambiguities (red circles) for CAS1-MCM4 vector in June 2001 (b)

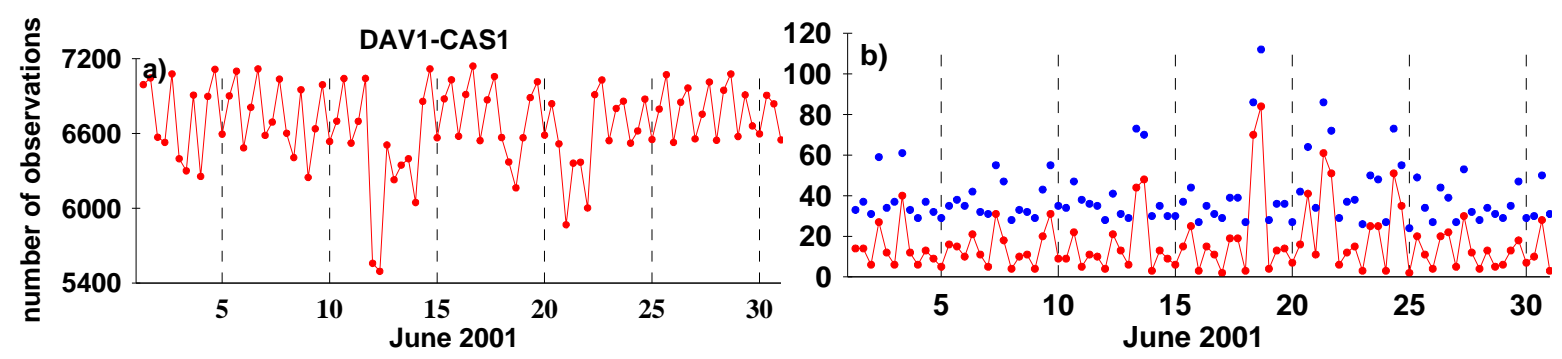

Fig. 13. Total number of observations of double-differences (a), the total number of all ambiguities (blue circles) and unresolved ambiguities (red circles) for DAV1-CAS1 vector in June 2001 (b)
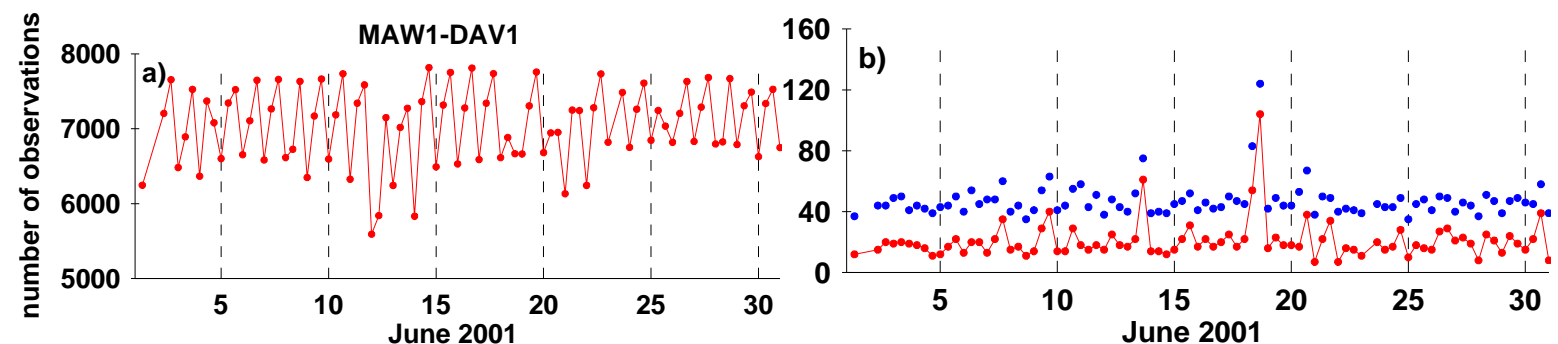

Fig. 14. Total number of observations of double-differences (a), the total number of all ambiguities (blue circles) and unresolved ambiguities (red circles) for MAW1-DAV1 vector in June 2001 (b) 

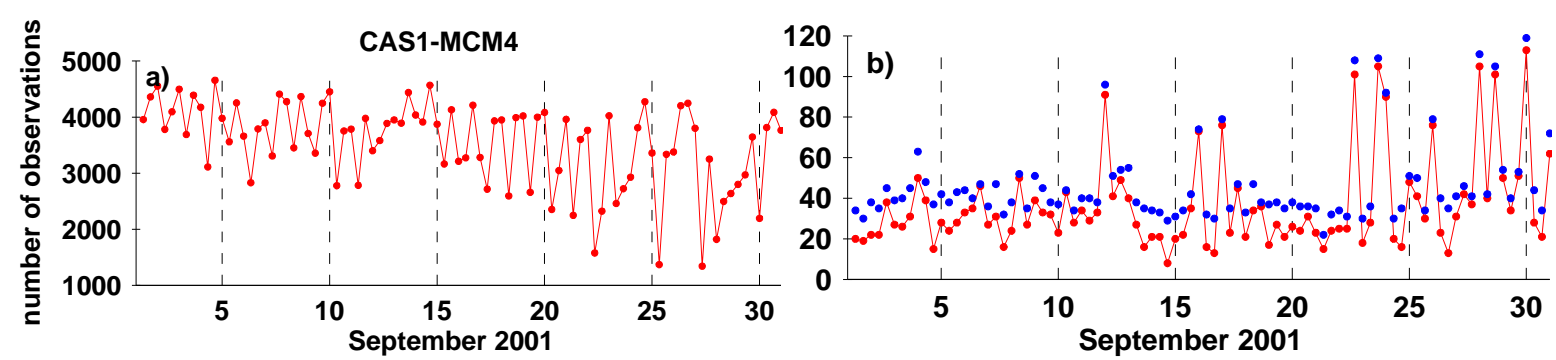

Fig.15. Total number of observations of double-differences (a), the total number of all ambiguities (blue circles) and unresolved ambiguities (red circles) for CAS1-MCM4 vector in September 2001 (b).

The clearly visible influence of the TEC fluctations on AR can also be observed for the baselines located in lower latitudes (in auroral region, 60-75 CGL). The deep TEC fluctations are not observed more frequently in the auroral than polar ionosphere. In this region, TEC fluctuations were detected in the order of 4-5 TECU/min only during severe geomagnetic storms. The results for auroral vectors (DAV1-CAS1 and MAW1-DAV1) are presented in Figs. 10-11, 13-14 and 16-17. For the shorter baseline (MAW1-DAV1), the analyzed impact is more pronounced. During the disturbed days of 11 April, 18 June and 23 September 2001, the total number of all ambiguities and unresolved ones reached its peak values: 160:140, 125:100 and 190:180, respectively (Figs 11, 14, 17).

For the longer vector (DAV1-CAS1), the results were also similar. It is clearly visible in Figs. 10, 13 and 16. The analyses of the disturbed day of 23 September 2001 when strong TEC fluctuations amounted to $4 \mathrm{TECU} / \mathrm{min}$ at 16-23 UT over the Davis and Casey stations, show that at the same time, the total number of DD observations over the DAV1-CAS1 vector decreased to 4200 (Fig 16a). Simultaneously, the total number of all ambiguities and unresolved ones increased sharply to 250 and 245, respectively (Fig. 16b).

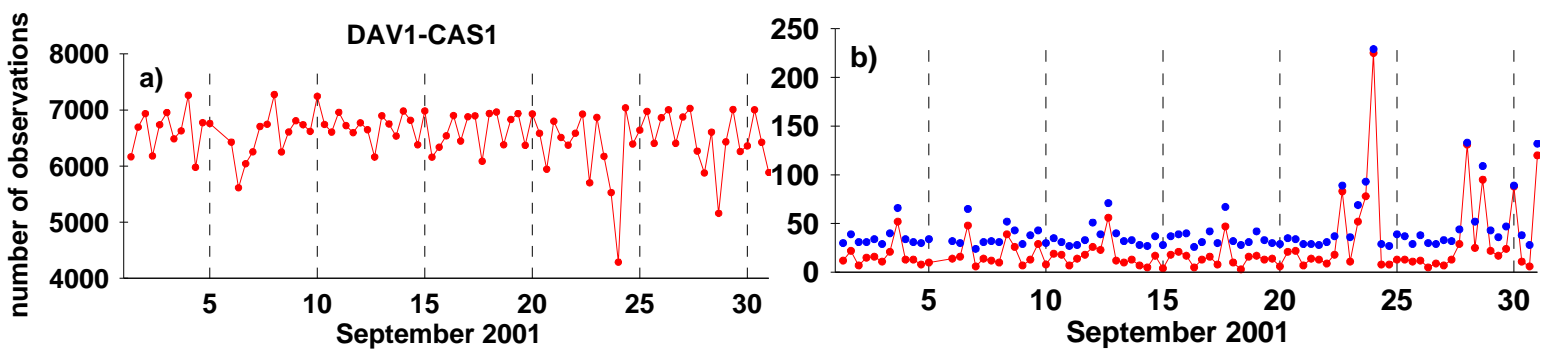

Fig. 16. Total number of observations of double-differences (a), the total number of all ambiguities (blue circles) and unresolved ambiguities (red circles) for DAV1-CAS1 vector in September 2001 (b)

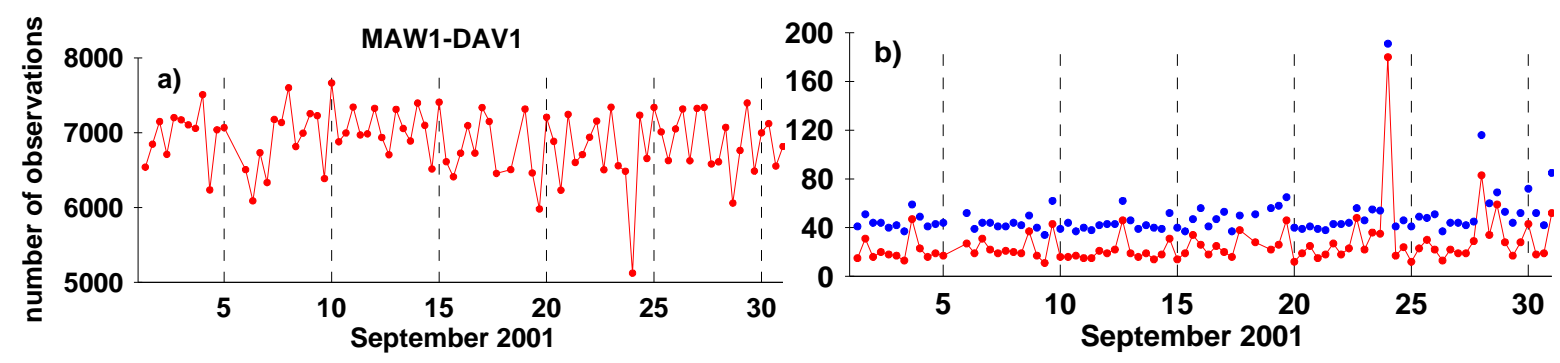

Fig. 17. Total number of observations of double-differences (a), the total number of all ambiguities (blue circles) and unresolved ambiguities (red circles) for MAW1-DAV1 vector in September 2001 (b) 
The comparison of the results, presented in Figs 9-17, from both quiet and stormy days with strong TEC fluctuations shows that storm-time ionospheric conditions disturbed the AR and consequently the accuracy of GPS positioning. During strong TEC fluctuations, the total number of unresolved ambiguities for CAS1-MCM4, DAV1-CAS1 and MAW1-DAV1 vectors increased from the level of the order 20 up to160, 245 and 180.

\section{CONCLUSIONS AND SUMMARY}

Data has been applied on the occurrence of strong TEC fluctuations to explain if detailed knowledge of the intensive and dynamic processes in the high-latitude ionosphere might be utilized to improve the repeatability of the vector components during severe geomagnetic disturbances. The current successful application of this data for precise GPS positioning leads to the following conclusions:

1. The strong TEC fluctuations strongly disturbed the AR and, consequently, the accuracy of GPS positioning.

2. The results show the exact dependence between the occurrence of medium and strong TEC fluctuations and the decrease in the total number of observations of double-differences (DD).

3. The occurrence of medium and strong TEC fluctuations also caused a significant increase in the total number of DD unresolved ambiguities (about 6 times).

4. This effect was detected over all latitudes.

The future analyses will include data on the occurrence of TEC fluctuations for improving ambiguity resolution in European latitudes, especially for RTK positioning with the use of more reliable DD ionospheric correction.

\section{ACKNOWLEDGEMENTS}

These studies have been supported by grant 5T12E 03323 of the Polish State Committee for Scientific Research.

\section{REFERENCES}

Aarons J., (1997): GPS system phase fluctuations at auroral latitudes, Journal of Geophysical Research, Vol. 102, A8, pp.17219-17231.

Aarons J., Mendillo M., Yantosca R., (1997): GPS phase fluctuations in the equatorial region during sunspot minimum. Radio Science, Vol. 32, No 4, pp. 1535-1550.

Aarons J., Lin B., Mendillo M., Liou K., Codrescu M., (2000): Global Positioning System phase fluctuations and ultraviolet images from the Polar satellite, Journal of Geophysical Research, Vol. 105, A3, pp.5201-5213.

Baran L.W., Shagimuratov I.I., Tepenitsina N.J., (1997): The use of GPS for ionospheric studies, Artificial Satellites, Vol. 32, No 1, pp. 49-60.

Basu Su., MacKenzie E., Basu S., Carlson H.C., Hardy D.A., Rich F.J., Livingston R.C., (1983): Coordinated measurements of low energy electron precipitation and scintillations TEC in the auroral oval, Radio Science Vol., 18, pp. 1151-1165.

Basu Su., Basu S., MacKenzie E., Coley W.R., Hanson W.R., Lin C.S., (1984): F region electron density irregularity spectra near auroral acceleration and shear regions, Journal of Geophysical Research, Vol. 89, pp. 5554-5564. 
Basu Su., Basu S., Eastes R., Huffman R.E., Daniell R.E., Chaturvedi P.K., Valladares C.E., Livingston R.C., (1993): Remote sensing of auroral E region plasma structures by radio, radar, and UV techniques at solar minimum, Journal of Geophysical Research, Vol. 98, 1569-1602.

Basu S., Groves K.M., Quinn J.M., Doherty P., (1999): A comparison of TEC fluctuations and scintillations at Ascension Island, Journal of Atmosphere and Solar-Terrestrial Physics, Vol. 61, pp. 1219-1226.

Coker C., Hunsucker R., Lott G., (1995): Detection of auroral activity using GPS satellites, Geophysical Research Letters, Vol. 22, No 23, pp. 3259-3262.

Doherty P., Raffi E., Klobuchar J., El-Arini M.B., (1994): Statistics of time rate of change of ionospheric range delay, In: Proceedings of ION GPS-94, Part 2, Salt Lake City, 1589 pp.

Hargreaves J.K., Burns C.J., (1996): Electron content measurements in the auroral zone using GPS: preliminary observations of the main trough and a survey of the degrees of irregularity in summer, Journal of Atmosphere and Terrestrial Physics, Vol. 58, pp. 14491457.

Hugentobler U., Schaer S., Fridez P. (eds), (2001): Bernese GPS Software Version 4.2, Astronomical Institute, University of Berne, February 2001.

Jakowski N., (1996): TEC Monitoring by Using Satellite Positioning Systems, Modern Ionospheric Science - A collection of Articles Published on the Occasion of the Anniversary: "50 Years of Ionospheric Research in Lindau", edited by Kohl H., Ruster R. and Schlegel K., European Geophysical Society, Katlenburg-Lindau, pp. 371-390.

Kersley L., Pryse S.E., Wheadon N.S., (1988a): Amplitude and phase scintillation at high latitudes over northern Europe, Radio Science, Vol. 23, pp. 320-330.

Kersley L., Chandra H., (1988b): Scintillation at high latitudes during winter magnetic storms, Journal of Atmosphere and Terrestrial Physics, Vol. 50, pp. 565-572.

Kersley L. Pryse S.E., Wheadon N.S., (1988c): Small scale ionospheric irregularities near regions of soft particle precipitation: scintillation and EISCAT observations, Journal of Atmosphere and Terrestrial Physics, Vol. 50, pp. 1047-1055.

Kersley L., Russell C.D., Pryse S.E., (1989): Scintillation and EISCAT investigations of gradient-drift irregularities in the high latitude ionosphere, Journal of Atmosphere and Terrestrial Physics, Vol. 51, pp. 241-247.

Kersley L., Russell C.D., Rice D.L., (1995): Phase scintillations and irregularities in the northern polar ionosphere, Radio Science, Vol. 30, pp. 619-629.

Krankowski A., Baran L.W., Shagimuratov I.I., (2002): Influence of the Northern Ionosphere on Positioning Precision, Physics and Chemistry of the Earth, Vol. 27, pp. 391-395.

Krankowski A., Shagimuratov I.I., Baran L.W., Ephishov I.I., (2005): Study of TEC fluctuations in Antarctic ionosphere during storm using GPS observations, Acta Geophysica Polonica, Vol. 53, No 2, pp. 205-218.

MacDougall J.W., (1990): Distribution of irregularities in the northern polar region determined from HILAT observations, Radio Science, Vol. 25, pp. 115-124.

Pi X., Manucci A.J., Lindqwister U.J., Ho C.M., (1997): Monitoring of global ionospheric irregularities using the worldwide GPS network, Geophysical Research Letters Vol 24, No 18, pp.2283-2286. 
Wanninger L., (1993): The occurrance of ionospheric disturbances above Japan and their effects on GPS positioning, Proceedings of the 8th International Symposium on Recent Crust Movemens (CRCM 93), pp.175-179, Kobe, Japan, December 6-11, 1993.

Wanninger L., (1995): Monitoring ionospheric disturbances using IGS Network, IGS Workshop Proceedings, Special Topics and New Direction, edited by Gendt G., and Dick G., pp. 57-66, Potsdam, May 15-18, 1995.

Zarraoa N., Sardon, E., (1996), Test of GPS for permanent ionospheric TEC monitoring at high latitudes, Annales Geophysicae, Vol. 14, pp. 11-19.

Received: 2005-10-17,

Reviewed: 2005-11-30, by I. Stanisławska,

Accepted: 2005-02-27. 